\title{
An integrated approach for supply chain tactical planning and cash flow valuation
}

\author{
Sabah Belil ${ }^{[1-2]}$, Asma Rakiz ${ }^{[1-3]}$ and Kawtar Retmi ${ }^{[1]}$ \\ ${ }^{1}$ Emines-Mohammed VI Polytechnic University, 43150 Ben Guerir, Maroc \\ ${ }^{2}$ LIMOS Clermont Auvergne University, Aubière, UMR CNRS 6158, Aubière, France \\ ${ }^{3}$ Paris II Panthéon-Assas University, 75006, Paris, France \\ \{Sabah.belil, Asma.rakiz, Kawtar.retmi\} @emines.um6p.ma
}

\begin{abstract}
This paper presents a methodology combining a flow optimization and a cost models in order to, simultaneously, realize a tactical planning of a productive system, and evaluate the financial performance of the proposed plans. The system addressed is a multi-site, multi-product supply chain structure with finite capacities of production, storage and transport. In order to model physical flow, we propose an optimization model taking into consideration all the physical system's constraints. It calculates production and transport plans while maximizing demand satisfaction rate. Then, in order to financially evaluate the solution found by the optimization model, we propose a cost model using Activity Based Costing $(\mathrm{ABC})$ as a valuation method using cost drivers mechanism. Finally, in order to couple both optimization and cost models in a global integrated model, we use an approach called PREVA for PRocess EVAluation, generally used to set up a supply chain's management control system using financial and physical metrics.
\end{abstract}

Keywords: Cost model, Linear programming model, Financial valuation.

\section{$1 \quad$ Introduction}

The supply chain is defined as a network composed of physical entities (factories, workshops, warehouses, etc.) crossed by flows (financial, material, informational, etc.), grouped into an integrated logistic process [1]. Thus, the supply chain management consists of modelling a set of flows, to manage them in an integrated way, and to improve their coordination to create value for the final customer [2]. A supply chain is crossed at least by three flows [3]: the physical flow (purchase of the raw material, transformation into finished product, and delivery to the customer). The financial flow, its optimization aims at satisfying the actors who contributed to the functioning of the supply chain. The information flow, which allows to coordinate between the two flows. The aim of our paper is to evaluate a supply chain performance by presenting the integration of physical and financial flows across the chain. [4] [5] propose a methodology for analyzing supply chain performance in terms of the management of assets and flow of cash along the supply chain. 
The purpose is to formalize relationships between physical and financial flow by their integration in tactical planning for an internal supply chain. The proposed approach allows the use of budgeting in order to evaluate the tactical production planning by integrating financial parameters such as payments terms into valuation models Activity Based Costing ( $\mathrm{ABC}$ ), and by coupling these kind of models with the tactical model. The rest of the article is organized as follows. In section 2 a review of the literature is presented. Section 3 gives a detailed description of the modeling framework for supply chain evaluation. Finally, section 4 conclude this paper.

\section{$2 \quad$ Literature review}

In this literature review, we first study tactical planning in multi-site supply chain. In the second part, we address literature that present $\mathrm{ABC}$ valuation method as a tool for building a cost model of an industrial system. Finally, we present some literature that link physical and financial models.

\subsection{Multi-level tactical planning}

Tactical planning deals with decisions about materials flow, inventory and capacity utilization during with a planning horizon from one or several months to two years. The main objective at this stage is to improve the cost efficiency (inventory) and the customer's satisfaction. In the hierarchical decision-making environment described above, lot-sizing decisions fall into the categories of either tactical or operational level. Many researchers have been interested in supply chain tactical planning using the lot sizing problem. The literature proposing its modelling is diverse and varied. Most of these papers propose mathematical models in order to achieve this goal. Multi-level lot sizing models are the models used by excellence in order to grasp the problem of horizontal synchronization of the global supply chain. [6] propose a literature review of the lot sizing dedicated to supply chain. The basic multi-level model, called the Multi-Level Capacitated Lot Sizing Problem (MLCLSP), was proposed by [7]. Its purpose is to link the end-products demand with the needs for internal components using the Gozinto matrix. Starting with this basic model, researchers have developed multi-site models that solve different problems; we cite for instance [8], [9], and [10]. Although, the problems solved by these models have different configurations, the considered variables and activities are similar.

\subsection{A valuation method: Activity Based Costing}

According to a comparison of the various methods of cost calculation [11], no method can be excluded as each one is appropriate to a specific context. As part of our research, we chose the $\mathrm{ABC}$ valuation method as a tool. This choice was made in order to be able to move to Business Units (BUs) oriented industrial process in the context of an industrial system. And this, to be able to be coupled to optimization models, from industrial management control systems that are associated with cost centers per functional entity. 
$\mathrm{ABC}$ can improve organizational performance in a number of ways: helping organizations become more efficient; provide organizations with a clear picture of where funds are spent; offer organizations a better alternative to the product based on cost; identify value-added activities and eliminate or reduce non-value-added activities. $\mathrm{ABC}$ provides organizations with a better understanding of cost formation using a causal approach through driver mechanics and identifies action levers leading to better organizational performance. In order to build a Decision Support System (DSS) linking optimization models to management control, we should focus on approaches combining optimization models and cost models.

\subsection{Coupling and review analysis}

Many works have been done on the product flow in supply chain whereas there is a little research works on the financial aspect of the supply chain. Traditional approaches for supply chain management usually focus on process operations and neglect the financial side of the problem. The study of supply chain manager interest for integration of financial impact in operational and tactical planning is done by [12]. [13] addresses the implementation of financial cross-functional links with the supply chain operations and retrofitting activities at plant level. In [14], the authors estimate the shareholder wealth effects of supply chain glitches that resulted in production or shipment delays. [15] considers a cash management problem of firms in a two-asset setting. [16] define an approach to assess the nature of a sale point based on supply chain activity. [17] and [18] present a methodology to solve the problems of efficiency, process control, and discrete production system cost management. [19] present the activity based costing method in combination with a discrete event simulation as a part of a discrete supply chain. [20] propose a model for the optimization of a global supply that maximizes the after tax profits in strategic planning. In [21], authors study the impact of financing constraints on inventory and cash management. [22] examines the relationship between liquidity management, operating performance and corporate value for firms.

Table 1. Literature analysis

\begin{tabular}{|c|c|c|c|c|c|c|c|}
\hline \multirow[b]{2}{*}{ Authors } & \multicolumn{3}{|c|}{ Decision level } & \multirow[b]{2}{*}{ Physical flow } & \multirow[b]{2}{*}{ Modeling approach } & \multirow[b]{2}{*}{ Financial flow } & \multirow[b]{2}{*}{ Modeling approach } \\
\hline & Strategic & $\begin{array}{c}\text { Tactical } \\
\end{array}$ & Operational & & & & \\
\hline$[13]$ & & $\mathrm{x}$ & & $\mathrm{X}$ & Mixed integer linear programming & $\mathrm{x}$ & Net present value( $(\mathrm{NPV})$ method \\
\hline$[14]$ & $\mathrm{X}$ & & & $\mathrm{X}$ & Linear programming & $\mathrm{X}$ & $\begin{array}{l}\text { Statistics methods } \\
\end{array}$ \\
\hline [15] & $\mathrm{x}$ & & & & & $\mathrm{X}$ & Diffusion approximation technique \\
\hline$[16]$ & $\mathrm{X}$ & & & $\mathrm{X}$ & Discrete event simulation & $X$ & Activity Based Costing method \\
\hline$[5]$ & & & $\mathrm{X}$ & $\mathrm{X}$ & Linear programming & $\mathrm{X}$ & Linear programming \\
\hline$[12]$ & & $\mathrm{X}$ & $\mathrm{X}$ & $\mathrm{X}$ & $\begin{array}{l}\text { Linear programming } \\
\end{array}$ & $X$ & $\begin{array}{l}\text { Statistics methods } \\
\end{array}$ \\
\hline$[20]$ & $\mathrm{X}$ & & & $\mathrm{x}$ & Linear programming & $\mathrm{X}$ & Linear programming \\
\hline [17] & $\mathrm{X}$ & & $\mathrm{X}$ & $\mathrm{X}$ & Discrete event simulation & $\mathrm{X}$ & Activity Based Costing method \\
\hline [4] & & & $\mathrm{X}$ & $\mathrm{X}$ & Linear programming & $\mathrm{X}$ & Linear programming \\
\hline [23] & & $\mathrm{X}$ & & $\mathrm{X}$ & Discrete event simulation & $\mathrm{X}$ & Activity Based Costing method \\
\hline$[22]$ & & $\mathrm{X}$ & & $\mathrm{X}$ & Linear programming & $\mathrm{X}$ & Statistics methods \\
\hline$[18]$ & & $\mathrm{x}$ & & $\mathrm{x}$ & Discrete event simulation & $\mathrm{x}$ & Activity Based Costing method \\
\hline [21] & & $\mathrm{X}$ & $\mathrm{X}$ & & Linear programming & $\mathrm{X}$ & Linear programming \\
\hline$[19]$ & & $\mathrm{X}$ & & $\mathrm{X}$ & Discrete event simulation & $\mathrm{X}$ & Activity Based Costing method \\
\hline
\end{tabular}

A synthesis of the different studied papers, carrying the integration of the physical and the financial flows, is given in a grid (Table 1); his grid indicates for each article studied, the decision-making level studied and the modeling technics. 


\section{An approach for the physical and financial flows assessment of the supply chain}

In this section we will present a detailed description of the modeling framework for supply chain evaluation.

\subsection{Designing a decision support system using PREVA}

In order to evaluate a supply chain based on the combined use of ABC method and the optimization model, we supposed to model the supply chain as a set of activities considers as Business Units and as autonomous entities belonging either to the entity of the supply chain or to a supplier/distributor who is integrated into the latter.

We therefore assume the existence of a supply chain made up of 1 to N BUs. In order to use the $\mathrm{ABC}$ models to evaluate processes, we propose to allocate, for each $\mathrm{BU}$ (a plant, a transport activity, etc.) made up of at least one elementary supply chain process, the different items that are required to translate physical flow activities into financial flow items. This phase is realized in our case using PREVA approach, it is used repeatedly to set up management control systems for the supply chain. The robustness of the approach has been shown several times [16] [18] [11]. The design and evaluation of activities by PREVA for supply chain involves three steps: (i) the first step deals with the evaluation of physical flow performance based on an optimization model. This step involves building a mathematical model of the studied system. (ii) In the second step, we have an action model for the financial flow that is done using the $\mathrm{ABC}$ method with a granularity at the pace of optimization. (iii) In the third step, the results are structured into prospective scorecards.

\subsection{Formalization for tactical production planning in multi-site supply chain structure.}

The propose Mixed Integer Linear Program (MILP) is a multi-level, multi-product multi-product supply chain structure. The problem is modeled using a small bucket multilevel lot sizing model. The productive system consists a set manufacturing and storage sites. Each site produces a set of products intended to meet both a final demand and an intermediate demand. This product structure is modeled by the Gozinto matrix, initiated by [7]. Each plant and inventory has a finite capacity. End-products can be stored in downstream or final inventories. Final products are transported by railway road to final inventories with a transport time. The train is limited by a maximum and minimum transport capacity. In order to satisfy the demand, the model calculates for each period, the production, storage and transported plans. We present below the mathematical model:

$S$ : Set of manufacturing sites; $I$ : Set of storage sites; $\mathrm{T}:$ Set of periods; $P$ : Set of products; $d_{i, t}$ : Final demand of a product $i$ at period $t ; a_{i, j}:$ The number of units of the product $i$ necessary to produce a unit of the product $j, a_{i, j, u}=0$ if $j<i$ ( $j$ predecessor of $i$ ); $\operatorname{Cap}_{i}$ : Maximum production capacity $\operatorname{inv}_{i}^{\text {int }}:$ Downstream inventory; $\operatorname{inv} v_{i}^{\text {fin }}$ : 
Final inventories; $I n v_{i}^{\max }:$ Maximum stock capacity; $S a t_{i, t}$ : Demand satisfaction rate; $P_{i, t, s}$ : Quantity of product $i$ to be produced at plant $s ; R_{i, t, s}:$ Quantity of product $i$ delivered by train from site $s$ to final stocks; $R_{\max }, R_{\min }$ : Maximum and minimum capacity of product to transported; $z_{i, i n v}$ : Transport time; $\beta_{i, s}$ : Binary parameter, it equals 1 if the product $i$ can be produced / stored in the plant / inventory.

$$
\begin{aligned}
& \operatorname{Max}_{i, t} \operatorname{Sat}_{i, t} \\
& \operatorname{In} v_{i, t, j}^{\text {fin }}=\operatorname{In} v_{i, t-1, j}^{\text {fin }}-s a t_{i, t} \cdot d_{i, t}, \forall i, t<z_{s, i n v}, j=m . . I \\
& \operatorname{In} v_{i, t, j}^{f i n}=\operatorname{In} v_{i, t-1, j}^{f i n}+\sum_{u} \cdot R_{i, t-z_{s, j}, s}-s a t_{i, t} \cdot d_{i, t}, \forall i, t \geq z_{s, i n v}, j=m . . I \\
& P_{i, t, s} \leq \operatorname{Cap}_{s}, \forall i, t, s \\
& \sum_{i} \operatorname{In} v_{i, t, j}^{\mathrm{int}} \leq \operatorname{In} v_{j}^{\max }, \forall i, t, j \\
& \sum_{i} \operatorname{In} v_{i, t, j}^{f i n} \leq \operatorname{In} v_{j}^{\max }, \forall i, t, j \\
& P_{i, t, s}<\beta_{i, s} \cdot \operatorname{Cap}_{s}, \forall i, t, s \\
& \operatorname{In} v_{i, t, j}^{\mathrm{int}}<\beta_{i, j} . \operatorname{In} v_{j}^{\max }, \forall i, t, j \\
& \operatorname{In} v_{i, t, j}^{\text {fin }}<\beta_{i, j} . \operatorname{In} v_{j}^{\max }, \forall i, t, j \\
& R_{i, t, s} \leq R_{\max }, \forall i, t, s \\
& R_{i, t, s} \geq R_{\min } . \omega_{i, t, s}, \forall i, t, s \\
& R_{i, t, s}-\mathrm{M} \omega_{i, t, s} \leq 0, \forall i, t, s \\
& \operatorname{In} v_{i, t, s}^{\mathrm{int}}, \operatorname{In} v_{i, t, s}^{f i n}, P_{i, t, s}, R_{i, t, s} \geq 0, \forall i, t, s \\
& \omega_{i, t, s} \in\{0,1\}, \forall i, t, s
\end{aligned}
$$

The Objective function (1) maximizes demand satisfaction rate. (2) is the stock balance equation of stocks. (3) and (4) are stock balance equations of final stocks. Constraints (5), (6) and (7) ensure the respect of the maximum production and inventory capacity respectively. Constraints (8) and (9) and (10) respectively assign the products to the plant / stocks in which they are produced / stored. Constraints (11) and (12) ensure maximum and minimum quantity limitations for transport by train. Constraints 
(12) and bind binary variables to corresponding decision variables. Finally, constraints

(14) and (15) define the domain of the decision variables.

\subsection{Cost Model}

Regarding the valuation model, initially, we did a distribution of charges. Since we have no operational decision related to fixed cost, as part of our modeling, we will consider direct and indirect variable costs. Relative to these costs, we have no problem in imputing the direct costs, otherwise, in order to impute the indirect costs, it is necessary to use the cost drivers. In a second step, we built our cost drivers. These drivers must reflect the consequences of the decisions made. We can have cost drivers linked to the line and others related to processors. Then, once we have cost drivers in the supply chain, we can move from existing industrial management control systems that are associated with cost centers per functional entity, to BUs process-oriented. The construction of an $\mathrm{ABC}$ model thus makes it possible to evaluate the value creation for each BU constituting the supply chain and making it possible to take into account all the inputs and outputs in each process entity. This model is then coupled with the optimization model.

In our case, we did a processor division to obtain the cost per quality and per hour. This file combines the direct cost and the support cost, the latter cost represents the cost of shutdowns $S C$ and maintenance $M C$ and the cost of running conditions $R C C$ plus the cost of energy $E C$ for each product. These support costs are calculated using cost inductors, running conditions inductors $R C I$, stop inductors $S I$, maintenance inductors $M I$ and energy inductors $E I$.

$$
\begin{gathered}
R C I=R C C \times R C \\
M I=M C \times(M D / D D M) \\
S I=S C \times(S D / D D M) \\
E I=E C \times P O E_{p r}
\end{gathered}
$$

Where $R C$ are the running conditions. $M D$ is the maintenance duration. $D D M$ is the duration of decision making. $S D$ is the stop duration. And $P O E_{p r}$ is the percentage of energy per processor. Finally, we calculated a margin, per hour and per quality. Once we did a cost model per line, per hour, and per processor for all outputs, we brought all the direct variable costs of all these outputs into one matrix.

\subsection{Implementation of the proposed approach to a chemical process industry}

In this section, we illustrate our model on real case of a chemical process industry. The program has been solved for one-month demand. It has realized the production planning of three products $\mathrm{P} 1, \mathrm{P} 2$ and $\mathrm{P} 3$ that can be produced in two plants F1 and F2 according to two scenarios. The first scenario consists of encouraging the production of the product $\mathrm{P} 1$ in plant $\mathrm{F} 1$ (product $\mathrm{P} 2$ can be produced simultaneously in plants $\mathrm{F} 1$ and F2). The second one consist of encouraging. The production of $\mathrm{P} 2$ in plant $\mathrm{F} 2$ rather 
than F1. Then, using the cost model, we financially evaluated the two proposed solutions in order to choose, economically, the best one.

Table 2. Coupling results (pro-format data)

\begin{tabular}{|c|c|c|c|c|c|c|c|c|c|c|}
\hline & $\begin{array}{c}\text { Produced quantity } \\
\text { (Plant Fl-scénario 1) }\end{array}$ & $\begin{array}{l}\text { Produced quantity } \\
\text { (Plant F2-scénario 1) }\end{array}$ & $\begin{array}{c}\text { Direct cost } \\
\text { (Dhs) }\end{array}$ & $\begin{array}{c}\text { Support } \\
\text { cost (Dhs) }\end{array}$ & $\begin{array}{c}\text { Total cost } \\
\text { (Dhs) }\end{array}$ & $\begin{array}{c}\text { Produced quantity } \\
\text { (Plant F1- scénario 2) }\end{array}$ & $\begin{array}{c}\text { Produced quantity } \\
\text { (Plant F2- scénario 2) }\end{array}$ & $\begin{array}{c}\text { Direct } \\
\text { cost (Dhs) }\end{array}$ & $\begin{array}{c}\text { Support } \\
\text { cost (Dhs) }\end{array}$ & $\begin{array}{c}\text { Total cost } \\
\text { (Dhs) }\end{array}$ \\
\hline 15/02/2017 01:00 & 258 & 272 & 4481 & 123 & 2441728 & 272 & 0 & 3585 & 123 & 1009739 \\
\hline 15/02/2017 02:00 & 258 & 272 & 4491 & 123 & 2446691 & 272 & 0 & 3583 & 123 & 1009229 \\
\hline 15/02/2017 03:00 & 0 & 272 & 4489 & 123 & 1255809 & 69 & 0 & 3584 & 123 & 257422 \\
\hline $15 / 02 / 201704: 00$ & 258 & 272 & 4491 & 123 & 2446691 & 272 & 0 & 3583 & 123 & 1009229 \\
\hline 15/02/2017 05:00 & 258 & 272 & 4481 & 123 & 2441728 & 272 & 0 & 3585 & 123 & 1009739 \\
\hline 15/02/2017 06:00 & 0 & 272 & 4491 & 123 & 1256357 & 0 & 39 & 3583 & 123 & 143207 \\
\hline 15/02/2017 07:00 & 258 & 272 & 4489 & 123 & 2445625 & 0 & 0 & 3584 & 123 & 0 \\
\hline 15/202/2017 08:00 & 132 & 0 & 4494 & 123 & 610455 & 272 & 39 & 3583 & 123 & 1152211 \\
\hline
\end{tabular}

Each hypothesis is simulated using the DSS proposed in the previous section. The accounting and physical data of a month were used in the real case to validate the operation of the system. The results proposed here are based on pro forma data. Table 2 presents the results. The analysis of the results shows that over the period of analysis and taking into account the data used, the production of P2 in plants F1 and F2 (Hypothesis 1) is not relevant from a financial point of view. So, our DSS can give an economic lighting.

\section{Conclusion}

In conclusion, we proposed and integrated approach combining two model: a flowplanning model and a financial valuation model. Mixing the approach aim to model and plan physical flows, on the one hand, and to evaluate the financial performance of the found solution on the other. Physical flow planning model is realized by a MILP model proposed to solve a multi-level, multi-product lot-sizing problem. Financial flow is modeled using ABC valuation method using cost drivers mechanism. In order to combine the models, we propose PREVA approach, method that models supply chain subsystems by Business Units.

\section{$5 \quad$ References}

1. Fenies, P., Gourgand, M., Tchernev, N.: A framework for supply chain performance evaluation. In: Congresso Internacional de pesquisa em logistica. pp. 1-12 (2004a).

2. Pagh, J.D., Lambert, D.M., Cooper, M.C.: Supply Chain Management: More Than a New Name for Logistics. Int Jrnl Logistics Management. 8, 1-14 (1997).

3. Lapide, L.: What about measuring supply chain performance. Achieving Supply Chain Excellence Through Technology. 2, 287-297 (2000).

4. Guillen-Gosalbez, G., Guillén, G., Badell, M., Puigjaner, L.: A holistic framework for shortterm supply chain management integrating production and corporate financial planning. International Journal of Production Economics. 106, 288-306 (2007).

5. Gupta, S., Dutta, K.: Modeling of financial supply chain. European Journal of Operational Research. 211, 47-56 (2011). 
6. Brahimi, N., Dauzere-Péres, S., Najid, N., Nordli, A.: Etat de l'art sur les problemes de dimensionnement des lots avec contraintes de capacité. In: Conférence Francophone de MOdélisation et SIMulation. pp. 385-392 (2003).

7. Billington, P.J., McClain, J.O., Thomas, L.J.: Mathematical Programming Approaches to Capacity-Constrained MRP Systems: Review, Formulation and Problem Reduction. Management Science. 29, 1126-1141 (1983).

8. Gnoni, M.G., Iavagnilio, R., Mossa, G., Mummolo, G., Di Leva, A.: Production planning of a multi-site manufacturing system by hybrid modelling: A case study from the automotive industry. International Journal of Production Economics. 85, 251-262 (2003).

9. Thierry, C., Supply chain management, models and implementation for medium-term decision support. University habilitation Memory to Conduct Research, Toulouse II Le Mirail University (2003)

10. Spitter, J.M., Hurkens, C. a. J., A. G. Kok, D., Lenstra, J.K., Negenman, E.G.: Linear programming models with planned lead times for supply chain operations planning. European Journal of Operational Research. 163, 706-720 (2005).

11. Retmi, k, An approach for an economic evaluation of operational and tactical decisions: implementation on the OCP supply chain. Phd Thesis: Paris Nanterre University et ENSEMHassan II University (2018)

12. Vickery, S.K., Jayaram, J., Droge, C., Calantone, R.: The effects of an integrative supply chain strategy on customer service and financial performance: an analysis of direct versus indirect relationships. Journal of Operations Management. 21, 523-539 (2003).

13. Badell, M., Romero, J., Puigjaner, L.: Optimal budget and cash flows during retrofitting periods in batch chemical process industries. International Journal of Production Economics. 3, 359-372 (2005).

14. Hendricks, K.B., Singhal, V.R.: The effect of supply chain glitches on shareholder wealth. Journal of Operations Management. 21, 501-522 (2003).

15. Premachandra, I.M.: A diffusion approximation model for managing cash in firms: An alternative approach to the Miller-Orr model. European Journal of Operational Research. 1, 218-226 (2004).

16. Fenies, P., Lagrange, S., Tchernev, N.: A decisional modelling for supply chain management in franchised networks: application in franchise bakery networks. Production Planning \& Control. 21, 595-608 (2010).

17. Chan, K.K., Spedding, T.A.: An integrated multidimensional process improvement methodology for manufacturing systems. Computers \& Industrial Engineering. 44, 673-693 (2003).

18. Comelli, M., Modélisation, optimisation et simulation pour la planification tactique des chaînes logistiques (phdthesis). Université Blaise Pascal - Clermont-Ferrand II (2008).

19. Mahal, I., Hossain, A.: Activity-Based Costing (ABC) - An Effective Tool for Better Management. Research Journal of Finance and Accounting. 10 (2015).

20. Vidal, C.J., Goetschalckx, M.: A global supply chain model with transfer pricing and transportation cost allocation. European Journal of Operational Research. 129, 134-158 (2001)

21. Brown, W., Haegler, U.: Financing constraints and inventories. European Economic Review. 48, 1091-1123 (2004).

22. Wang, Y.-J.: Liquidity management, operating performance, and corporate value: evidence from Japan and Taiwan. Journal of Multinational Financial Management. 12, 159-169 (2002).

23. Lange, J., Bergs, F., Weigert, G., Wolter, K.-J.: Simulation of capacity and cost for the planning of future process chains. International Journal of Production Research. 50, 6122-6132 (2012). 